\title{
Solid Dispersion Immediate Release Tablet Dosage Form
}

National Cancer Institute

\section{Source}

National Cancer Institute. Solid Dispersion Immediate Release Tablet Dosage Form. NCI

Thesaurus. Code C162112.

A solid dosage form containing one or more active pharmaceutical ing redient which can be dispersed in a carrier at solid state, and immediately released upon administration. 